\title{
Regulatory Modes and Entrepreneurship: The Mediational Role of Alertness in Small Business Success
}

\author{
by Clara Amato, Robert A. Baron, Barbara Barbieri, Jocelyn J. Bélanger, and \\ Antonio Pierro
}

Previous studies suggest that entrepreneurs play a key role in the success of their ventures. But relatively little is currently known about how they produce such effects. The present research provides data suggesting that two modes of entrepeneurs' self-regulation-locomotion and assessment-enhance a firm's success through their effects on the components of alertness. This mediational model was tested and supported with data from 120 entrepreneurs. Locomotion was positively related to the scanning and search component, while assessment was positively related to the association and evaluation components. These findings are discussed in terms of the role of founders' self-regulation in the performance of their companies.

\section{Introduction}

Given the central role of small and mediumsized companies in promoting a healthy market economy (Acs 1992; Hillary 2000), it is becoming increasingly important to understand how these firms achieve success. Previous research has reported a positive relationship between some individual characteristics and the success of new ventures (Brandstätter 2011; Leutner et al. 2014; Rauch and Frese 2007a,b; Shane and Nicolaou 2013; Zhao, Seibert, and Lumpkin 2010). The question of how founders' personal characteristics influence business success, however, remains somewhat unclear. Specifically, previous studies suggest the existence of intervening variables in the relationship between founders' personal characteristics and firm performance (Rauch and Frese 2000).

With respect to such mediational models (see Baum and Locke 2004), most attention has been directed to behavioral variables. For instance, it has been found that training programs (Miron and McClelland 1979), motivation (Herron and Robinson 1993), planning (Rauch and Frese 1997), strategies (Göbel and Frese 1999), and goals (Baum and Locke 2004) are positively related to business performance. However, little attention has paid to the potential role of specific entrepreneurial abilities in enhancing this relationship (see Baum, Locke, and Smith 2001; Sambasivan, Abdul, and Yusop 2009 for exceptions to this overall pattern).

Clara Amato is research fellow in the Department of Social and Developmental Psychology at University of Rome 'La Sapienza.'

Robert A. Baron is professor in the School of Entrepreneurship at Oklahoma State University.

Barbara Barbieri is professor in the Department of Social and Developmental Psychology at University of Rome.

Jocelyn J. Bélanger is professor in the Department of Psychology at New York University Abu Dhabi, United Arab Emirates.

Antonio Pierro is professor in the Department of Social and Developmental Psychology at University of Rome.

Address correspondence to: Clara Amato, Department of Social and Developmental Psychology, University of Rome 'La Sapienza,' Rome, Italy. E-mail: amatoclara@gmail.com. 
In the present research, we suggest that specific aspects of self-regulation-locomotion and assessment regulatory modes (Higgins, Kruglanski, and Pierro 2003; Kruglanski et al. 2000)play a role in small business success. Consistent with previous findings, we propose that such effects are indirect, that is, operating through intervening cognitive processes related to alertness (scanning, making associations, evaluative judgment; Tang, Kacmar, and Busenitz 2012).

To further explicate the nature of this model and its foundations in previous theory and research, we first briefly review relevant literature on regulatory modes and alertness, describing the theoretical foundations upon which the current model and research hypotheses are based. Then, we report the findings of research designed to test these hypotheses.

\section{Regulatory Modes and Entrepreneurial Success}

In recent years, research has found that individuals engage in goal-pursuit in one of two regulatory modes described by the terms locomotion and assessment (Higgins, Kruglanski, and Pierro 2003; Kruglanski et al. 2000, 2010). Locomotion "constitutes the aspect of selfregulation concerned with movement from state to state and with committing the psychological resources that will initiate and maintain goalrelated movement in a straightforward and direct manner, without undue distractions or delays" (Kruglanski et al. 2000, p. 794). In short, it is an approach that emphasizes doing (taking action) and, for individuals especially high in locomotion, the sooner the better.

In contrast, assessment "constitutes the comparative aspect of self-regulation concerned with critically evaluating entities or states, such as goals or means, in relation to alternatives to judge relative quality" (Kruglanski et al. 2000, p. 794). Under this mode, individuals approach action cautiously, and do not proceed until they have evaluated all relevant factors and possible means of proceeding. In essence, assessors want to be sure that they will "do it right" when they do proceed, and they are more concerned with moving ahead in effective ways than with merely getting started.

Regulatory mode theory proposes that locomotion and assessment are stable individual difference variables as well as situational variables (situations may cause one mode to predominate over the other) (Avnet and Higgins 2003; Higgins et al. 2003).

Interestingly, these two functional dimensions of self-regulatory activities are relatively independent; thus, individuals can be high or low on each, so that, for instance, a specific founder can be high in locomotion and high in assessment, high in locomotion and low in assessment, low in both, and so on. As we will describe below, these different patterns have important implications for opportunity recognition process (by means of alertness), and for organizational performance.

Regulatory modes have implications for behaviors in various domains, including several aspects of work-related functioning. For instance, locomotors have a high behavioral activation, a high commitment to action maintenance (Higgins et al. 2003) and tend to experience high levels of intrinsic task-motivation. Similarly, people with high levels of locomotion tend to exert more effort in work contexts, and are more strongly influenced, in such behavior, by job involvement and effort commitment (Pierro, Kruglanski, and Higgins 2006a). Assessors, who have high self-evaluation concern and are sensitive to social appraisal and social norms, are focused on "doing it right" and tend to experience high levels of extrinsic taskmotivation (Pierro, Kruglanski, and Higgins 2006b). Some evidence from organizational contexts revealed that groups composed of locomotors are faster while groups composed for assessors are more accurate in their overall task performance, and, more interestingly, that mixed groups contribute to performance, that is, both fast and accurate (Mauro et al. 2009). Prior research has shown that both locomotion and assessment can contribute to self-regulatory success (Higgins et al. 2003; Kruglanski et al. 2000) and that optimal self-regulation process should usually utilize both modes of selfregulation suggesting that "going in the right direction" requires that locomotion and assessment work together at intrapersonal level too (Pierro et al. 2012, p. 250).

Both regulatory modes may be related to the success of entrepreneurial opportunity recognition process: the desire for locomotion may lead founders to movement toward a potential business opportunity, the tendency for assessment may lead founders to find the best alternative before moving ahead.

To date, however, regulatory modes theory has not been investigated in relation to 
entrepreneurship. This is somewhat surprising, because there are several reasons to believe that regulatory modes can predict important entrepreneurial outcomes. With regard to the specific relationship between founders' characteristics (including certain aspects of personality) and firm' success, there is empirical evidence indicating that some characteristics correlated with regulatory modes are also related to firm performance. These include proactivity (a characteristic of locomotors, Kruglanski et al. 2000; Tornau and Frese 2013) and generalized selfefficacy, as well as openness to experience (a characteristic of assessors, Kruglanski et al. 2000; Rauch and Frese 2007b; Zhao et al. 2010). Additional personal characteristics such as conscientiousness (Ciavarella et al. 2004), emotional stability (Brandstätter 1997), extraversion (Leutner et al. 2014), and need for achievement (Collins, Hanges, and Locke 2004)—which are correlated with locomotion (Kruglanski et al. 2000)— - have been found to be related to several indicators of firms' success, such as longevity of a business, perceived business success, a combination of entrepreneurial success outcomes, performance (sales growth, stock growth), respectively. Together, this past research suggests that various dispositional characteristics shown by founders are significantly related to new venture success (see also, Baron, Tang, and Hmieleski 2011). We suggest here that dispositional tendencies to approach self-regulation through locomotion or assessment play a similar role. However, as noted below, we further suggest that this role involves the intervening influence of the components of entrepreneurial alertness, that is, active scanning and search, association and connection, and evaluation and judgment.

\section{Entrepreneurial Alertness}

Alertness to business opportunities is central in entrepreneurship theory; it represents the cognitive engine driving the opportunity identification process (Gaglio and Katz 2001; Kaish and Gilad 1991). In the past, alertness was a term generally applied to an individual's ability to notice opportunities that have been overlooked by others (Kirzner 1973, 1979). However, recent literature has examined the nature of alertness from a cognitive perspective, and found that it involves three major components: (1) active search and scanning for opportunities; (2) association and connection; and (3) evaluation and judgment-evaluating the potential value of identified opportunities (Tang 2009; Tang et al. 2012; Yu 2001). These components constitute three steps of the same process. The scanning phase is an active and regular search for information, so it can proceed in a relatively "automatic" manner rather than in a conscious and carefully directed one (Baron 2006; Baron and Shane 2008). This phase provides individuals with valuable information, that together constitutes their broad store of knowledge in a particular domain; the collected information can then be manipulated and, using a wide range of knowledge, may help individuals to "think out of the box" in the next phase. The phase of association and connection rather than a specific behavior of information seeking refers to a general and stable cognitive ability of entrepreneur to "connect dots"; this phase permits to "alert founders" to recognize patterns in new information (e.g., Baron 2006; Dyer, Gregersen, and Christensen 2008; Tang et al. 2012). Finally, prior knowledge and information, if framed appropriately, increases the likelihood of careful evaluation of the potential opportunity. The phase of evaluation and judgment refers to a crucial process in which the entrepreneurs must answer the question: "Is this really a viable (i.e., potentially profitable) business opportunity?" Often, an entrepreneurial idea made in early stages is refined as a result of feedback processes and it may then no considered an opportunity. In this way, the cognitive processes involved in the opportunity identification may be nonlinear and receive an iterative and cyclical character (Braun and aus Bornheim 2007; Gaglio 2004; Gaglio and Katz 2001).

Overall alertness constitutes the pre-actional phase of entrepreneurial behavior and precedes the active steps involved in developing an identified business opportunity into a new venture (Tang et al. 2012). Thus, it is concerned with deliberation and engagement with the content of the decision to decide whether or not to commit to entrepreneurial action. In this sense, regulatory modes may play an important role in determining alertness. In fact, Scholer and Higgins (2012) study on regulatory modes and deliberation provides support for this suggestion, indicating that both locomotion and assessment are involved in pre-actional phase of selfregulation.

\section{Alertness and Firm Success}

Rather than focusing on its antecedents, the literature on alertness has generally focused on 
its potential outcomes. It has been shown that individuals high in entrepreneurial alertness are more likely to form the intention of starting a business (van Gelderen et al. 2008) and also have greater likelihood than individuals low in alertness of acting on these intentions-actually engaging in startup activity (Shane, Kolvereid, and Westhead 1991). Furthermore, there is empirical evidence suggesting that alertness is positively related to a firm's innovativeness (Tang et al. 2012). In this context, it is important to note that identifying and selecting the most appropriate and potentially profitable opportunities for a new business are among the most important activities carried out by entrepreneurs (Stevenson, Roberts, and Grousbeck 1985).

We also agree with Ardichvili, Cardozo, and Ray (2003) and many others in suggesting that the creation of a successful business derives, at least in part, from successful opportunity identification. This, in turn, includes recognition of an opportunity (which often derives from access to valuable information and association of various trends and events) and the accurate evaluation of this opportunity. Indeed, as suggested by Markman and Baron (2003), a strong link exists between the ability to recognize opportunities (i.e., the evaluation component of alertness) and entrepreneurial success. In short, previous research indicates that all three components of entrepreneurial alertness play an important role in successful opportunity recognition, and as noted earlier, opportunity recognition in turn often contributes significantly to a new venture's success (Baron 2007).

\section{The Present Research: Testing a Model of Regulatory Mode, Alertness, and Firm Performance}

The present research examines the role of regulatory modes as important antecedents of alertness and subsequent firm success. In particular, we suggest that all three components of alertness (scanning and search; association and connection; evaluation and judgment) will be related to regulatory modes but in somewhat different ways. In particular, to the extent that locomotion involves heightened activity level, and therefore is positively associated with measures of energy, task orientation, and a focus on "doing," we propose that it will be associated with the first component of alertness identified by Tang et al. (2012): active scanning and search. Indeed, this alertness component is related to active information search, which is closely related to creativity (Tang et al. 2012). Consistent with reasoning, Kickul et al. (2009) suggest that creative thinking that relies on intuition plays a key role in this searching stage. It is also notable that locomotors are more likely to use intuition versus effortful analytic style in their decision making process (Weber and Lindemann 2011). Similarly, Baas, De Dreu, and Nijstad (2008) suggest that locomotion may be related to this first phase of alertness process. In support of these suggestions, previous studies have shown that the effects of positive affect on creativity are greater when positive affect is combined with high levels of activation (Baas et al. 2008) and with a promotion regulatory focus (Higgins 2006). However, it is worthy to note that despite the fact that creative thinking, intuitive cognitive style and locomotion correlate with the same variables, they are distinct constructs. For example, a person high in locomotion might engage in activities that are intrinsically motivated (i.e., their motivation is to stay in motion), whereas intuitive cognitive style pertains to affect-driven behavior (Betsch 2011). Also, locomotors set their goals (e.g., making a list of priorities or scheduling) (Amato et al. 2014) to save time and to be punctual; they have high scores in preference for order (Amato et al. 2014) and high levels of conscientiousness (Kruglanski et al. 2000). In contrast, individuals, who score high in intuitive (versus analytic) cognitive style have low scores in conscientiousness (Witteman, van den Bercken, Claes, and Godoy 2009) and a preference for unstructured work environments (Brigham, Castro, and Shepherd 2007).

There do not appear to be strong grounds for suggesting that locomotion would be associated with the association and connection or with evaluation and judgment phases, because locomotion emphasizes current action rather than careful evaluation of various alternatives.

Thus, this following hypothesis was proposed:

\section{H1: There is a positive relationship between entrepreneurs' locomotion orientation and their participation in active scanning and search of information.}

Conversely, assessment would be expected to be related to the association and connection 
component of alertness. High scores on association and connection components are indicative of entrepreneurs' "tendency to consider multiple options and possibilities to make unique connections, even when this means increasing the distractions" (Tang et al. 2012, p. 9). At the same time, because assessment is primarily concerned with identifying the most effective means of proceeding and with careful evaluation of various alternatives, we suggest that it will be positively related to the evaluation and judgment component of alertness. Previous studies on cognitive style and evaluation competency go in the same direction: the competency in judging and evaluating information seems to be positively related to the analytic cognitive style (Kickul et al. 2009), that in turn is associated to assessment (Weber and Lindemann 2011). Thus, we propose the following hypotheses:

\section{H2a: There is a positive relationship between entrepreneurs' assessment orientation and the association and connection component of alertness.}

\section{H2b: There is a positive relationship between entrepreneurs' assessment orientation and the evaluation and judgment component of alertness.}

With regard to firm success, some authors suggest that entrepreneurs are (1) generally more subject to an optimistic bias than other people (Cooper, Woo, and Dunkelberg 1988; Hmieleski and Baron 2009); (2) overconfident (Koellinger, Minniti, and Schade 2007); and (3) often use subjective criteria to evaluate an opportunity that they have identified (Baron 2006). These common biases could lead to an ineffective opportunity identification process, and ultimately, to the identification of an opportunity with little likelihood of success. This would be similar to a "false alarm" in signal detection theory: perception of an opportunity when, in fact, none exists. Nevertheless access to valuable information and putting it to good use are important, and can assist entrepreneurs in choosing between bona fide opportunities and ones that are, essentially dead ends (Baron 2006). On the basis of this reasoning, we offer the following hypothesis:

H3: There is a positive relationship between the care with which entrepreneurs' evaluate iden- tified opportunities and the subsequent performance of their new ventures.

More interestingly, we propose a mediational model in which the three components of alertness mediate the relationship between regulatory modes and success. Although relationships between regulatory modes and business success have not been established by prior research, meaningful hypotheses concerning such relationships can be generated on the basis of existing evidence. Previous studies, as noted earlier, indicate that the both modes can lead to good performance in several settings, including organizational contexts (Pierro et al. 2012), college achievement, successful military performance (Kruglanski et al. 2000), and team work (Mauro et al. 2009). In that vein, organizations are expected to attain higher levels of performance when entrepreneurs are high in both regulatory modes-locomotion and assessment.

In particular, we suggest that both regulatory modes will have a positive relationship with firm performance and that this relationship will be mediated by the components of alertness.

H4a: Locomotion will have an indirect effect on firms' success through scanning and search component of alertness (that, in turn predicts the other two components of alertness).

H4b: Assessment will have an indirect effect on firms' success through two components of alertness (association and connection; evaluation and judgment).

Figure 1 presents an overview of these predictions and the model tested in the present research.

\section{Method}

\section{Sampling Procedures}

Between March 2012 and May 2012 a total of 478 entrepreneurs in Sardinia (Italy) were contacted by telephone using the contact databases provided by the Small and Medium-Sized Enterprises (SMEs) Association of Sardinia (CONFAPI) and by Cagliari's Chamber of Commerce. The sampling procedures consisted of two phases. In the first phase trained interviewers telephoned the founders of SMEs asking for information to define the size of their firms. At this stage those 


\section{Expected Relationship between Regulatory Modes, Alertness Dimen- sions, and Small Firms' Success}

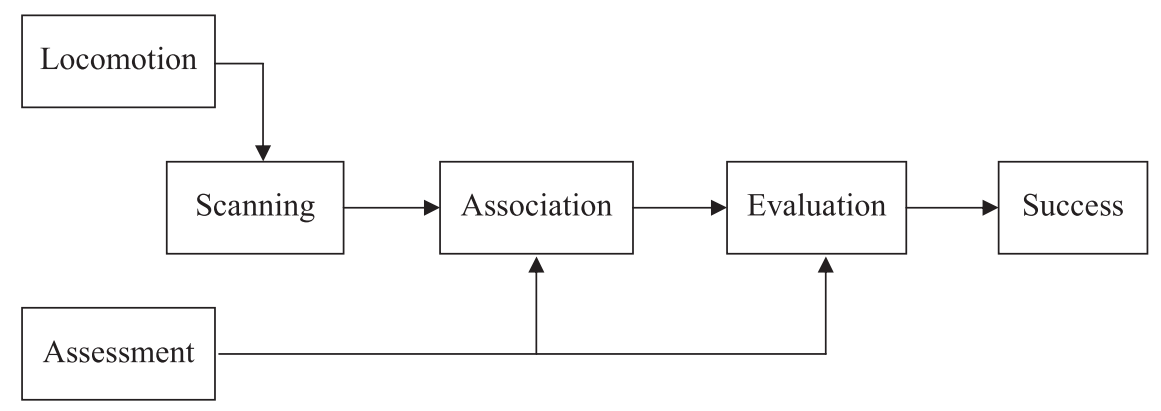

that did not qualify as small firms were excluded, while the founding entrepreneurs of small enterprises (SEs) were invited to participate in the study. The SEs are defined as firms that employ fewer than 50 persons and whose annual balance sheet total that does not exceed 10 million euros (European Union 2003). In the second phase, a self-administered questionnaire was emailed to entrepreneurs of SEs.

\section{Participants}

Out of the total number of businesses contacted (478), 10 were excluded, as they did not qualify as small firms, while 328 did not replied to the questionnaire. Finally, 20 have been excluded because of failure to respond to all items of the questionnaire.

The final sample consisted of 120 Sardinian entrepreneurs (the founders of SEs), 80 of whom were male and 30 female (10 entrepreneurs did not provide information about their gender) whose mean age was 48.88 years $(S . D .=10.95)$. As regards their education, 60.8 percent had finished upper secondary school, 26.7 percent had a degree, a master or a doctor's degree, 10 percent had dropped out of school after lower secondary school; 2.17 percent did not give any information on this subject. Concerning business information, the firms studied belonged to the tertiary economic sector (some examples of tertiary sector industries are entertainment, government, and hospitals) (87.5 percent) and the secondary sector (examples of secondary sector are car manufacturers, steel works, and builders) (12.5 percent), while none belonged to the primary sector (examples of primary sector are fishing, farming, and mining).
The mean age of the firms studied was 19.10 $(S . D .=16.75)$. Finally, all the firms studied were small businesses, according to the official European Union (2003) mixed definition of business size (including the number of employees and the annual balance sheet): 64.3 percent were micro businesses (with fewer than 10 employees and less than 2 million euros of annual balance) and 35.7 percent were small business (with fewer than 50 employees and less than 50 million euros of annual balance) (see Table 1).

\section{Measures}

All participants completed a questionnaire containing the short versions of the following scales:

Locomotion and Assessment Scales. Fourteen items were selected from the Italian versions of the Locomotion and Assessment Scales (Kruglanski et al. 2000). The short version constitutes two separate seven-item self-report measures designed to tap individual differences in these tendencies. Entrepreneurs rated the extent to which they agree with self-descriptive statements reflecting locomotion (e.g., "I enjoy actively doing things, more than just watching and observing") or assessment (e.g., "I spend a great deal of time taking inventory of my positive and negative characteristics"). Ratings were made on a six-point Likert type scale ranging from 1 (strongly disagree) to 6 (strongly agree). We computed two composite scores (one for locomotion and one for assessment) by averaging across responses. Previous studies with Italian samples have demonstrated that the locomotion and assessment scales have 
Annual Balance Sheet

$\begin{array}{lrrr}<10 & 64.3 \text { percent }^{\mathrm{a}} & 11.2 \text { percent }^{\mathrm{b}} & 75.5 \text { percent }^{\mathrm{b}} \\ <50 & 8.2 \text { percent }^{\mathrm{b}} & 16.3 \text { percent }^{\mathrm{b}} & 24.5 \text { percent } \\ \text { Total } & 72.5 \text { percent } & 27.5 \text { percent }^{2} & 100 \text { percent }\end{array}$

${ }^{\mathrm{a}}$ Micro-business; ${ }^{\mathrm{b}}$ Small business.

satisfactory reliability (Cronbach's $\alpha=0.82$ for the locomotion scale and 0.78 for the assessment scale) (Kruglanski et al. 2000). In the present sample, the reliability for the locomotion $(M=4.97, S . D .=0.75)$ and assessment $(M=3.77, S . D .=0.82)$ scale was 0.72 and 0.60 , respectively.

Alertness Scale. A short version (nine items) of the alertness scale developed by Tang and colleagues (2012) was administered. The scale measures three aspects of alertness namely scanning and search, association and connection, evaluation and judgment. Three items were used for each subscale. Scanning and search refers to information-seeking behaviors. Scanning is the alertness component, which provides the sensory input vital for the accumulation of new knowledge on a specific domain (e.g., "I read newspapers, magazines, or trade publications regularly to acquire new information"). This scale had a Cronbach's alpha of 0.68 in the present sample $(M=4.00$, $S . D .=0.82)$. Association and connection statements reflect the entrepreneurs' ability to "connect the dots." Individuals who have high scores on this scale connect to the big picture multiple options and possibilities in a creative manner (e.g., "I often see connections between previously unconnected domains of information"). This scale exhibited a Cronbach's alpha of 0.74 in the present sample $(M=3.92$, $S . D .=0.57)$. Evaluation and judgment includes items asking subjects to evaluate their ability to assess different opportunities and identify the best (e.g., "When facing multiple opportunities, I am able to select the good ones"). This scale exhibited a Cronbach's alpha of 0.73 in the present sample $(M=3.9$, S.D. $=0.64)$.
We computed three composite scores (one for each dimension) by averaging across responses to each item.

Entrepreneurial Success. To determine the level of entrepreneurial success of the firm we asked the entrepreneurs participating in the study to provide a subjective assessment consisting of evaluations of their own business (the perceived business success), according to the 14 items of the Entrepreneurial success scale (ES) developed by Amato (2013). These items are designed to assess key aspects of success, including financial performance, profitability, innovativeness (investment in R\&D and product innovation), overall performance, and reputation (the public image of the business). These dimensions are ones suggested by previous research (Lumpkin and Dess 1996; Venkatraman and Ramanujam 1986). Sample items: "How successful is your business?"; "How profitable is your business?"; "How much capital is available that can be directed by the company toward R\&D?." A five-point response scale was used ranging from 1 (not at all) to 5 (extremely). We performed an exploratory factor analysis from which emerged just one dominant factor (first four eigenvalues: $5.0,1.4,1.2$, and 1.1) with all factor loadings equal to or greater than 0.30 .

Amato (2013) demonstrated that the internal consistency of the ES is satisfactory $(\alpha=0.89)$. In the present study, the scale exhibited a Cronbach's alpha of $0.87(M=3.61 ; S . D .=0.50)$.

Three control variables relevant to entrepreneurial success were included (Murphy, Trailer, and Hill 1996): Size of the firm, age of the firm, and specific industry. Furthermore, individual control variables were included: the gender (dummy coded 0 for male, 1 for female), age, 
and educational level (1 "low," 2 "medium," and 3 "high"). ${ }^{1}$

\section{Convergent and Discriminant Validity of the Measures}

To assess the convergent and discriminant validity of regulatory modes, components of alertness and success measures we performed a confirmatory factor analysis (CFA) with six (correlated) latent factors (locomotion and assessment regulatory modes, scanning, association, evaluation, and success). The observed variables contained in the CFA model were represented by the nine items reflecting the three components of alertness (scanning, association, and evaluation) and, specifying the model as partial disaggregation model (Bagozzi and Heatherton 1994), by three aggregates of items for each of the remaining constructs (i.e., success, assessment, and locomotion). To further examine discriminant validity of the constructs, we compared the estimated six-factor model with three alternative models: one with five latent factors (one latent factor-regulation-underlying the two regulatory modes, scanning, association, evaluation, and success); one with four latent factors (locomotion and assessment regulatory modes, one latent factor underlying alertness components, and success); one with one latent factor (assuming a "general factor" underlying all the observed variables). CFA results show that the six-factor model $\left(\chi^{2}[120, N=120]=217.12, p=.00\right.$; comparative fit index $[\mathrm{CFI}]=0.91$; root mean square error of approximation [RMSEA] $=0.082$; standardized mean square residual $[\mathrm{SMSR}]=0.08$; nonnormed fit index $[\mathrm{NNFI}]=0.89$ ) fits the data better compared with the five-factor model $\left(\chi^{2}[125, N=120]=230.79, p=.00 ; \mathrm{CFI}=0.90\right.$; RMSEA $=0.084 ; \quad$ SMSR $=0.085 ; \quad$ NNFI $=0.88)$, the four-factor model $\left(\chi^{2}[129, \quad N=120]=\right.$ $332.05, \quad p=.00 ; \quad$ CFI $=0.83 ; \quad$ RMSEA $=0.12$; SMSR $=0.096$; NNFI $=0.80)$ and, finally, the onefactor model $\left(\chi^{2}[135, N=120]=533.88, p=.00\right.$; $\mathrm{CFI}=0.70 ; \quad$ RMSEA $=0.16 ; \quad$ SMSR $=0.12$; $\mathrm{NNFI}=0.65)$. The increase in fit of the six-factor over the five-factor model $\left(\Delta \chi^{2} \quad(5)=13.67\right.$ $p<.05)$, the four-factor model $\left(\Delta \chi^{2}(9)=114.93\right.$, $p<.001)$ and the one-factor model $\left(\Delta \chi^{2}\right.$ $(15)=316.76, p<.001)$ were all significant, thus supporting the distinction between the six constructs. In addition, these results demonstrate that the probability of common method variance occurring is minimized (i.e., inflating the relationship between constructs) (Iverson and Maguire 2000; Podsakoff et al. 2003).

Finally, the factor loading values of the sixfactor model were all significant and above 0.41 , thus demonstrating convergent validity for the constructs with multiple indicators (Bagozzi 1994).

\section{Main Analysis}

Means, standard deviations, and correlations for all measures are displayed in Table 2.

Regulatory Modes and Alertness Components. To test $\mathrm{H} 1, \mathrm{H} 2 \mathrm{a}$, and $\mathrm{H} 2 \mathrm{~b}$, multiple regression analyses were conducted.

In the first regression analysis, locomotion and assessment were regressed on scanning; in the second multiple regression analysis locomotion and assessment were regressed on association; in the third multiple regression analysis locomotion and assessment were regressed on evaluation. In each analysis the components of alertness that were not the criteria, firm size, firm age, industry, entrepreneurs' age, gender, and educational level ${ }^{1}$ have been inserted as covariates.

Results (see Table 3), supporting $\mathrm{H} 1$, indicated that locomotion $(\beta=0.34, p<.001)$ (controlling for the association and the evaluation components of alertness, and for the control variables), was related to scanning, whereas assessment was not $(\beta=0.03, p=.76)$.

Consistent with our $\mathrm{H} 2 \mathrm{a}$, results of the second multiple regression analysis indicated that assessment ( $\beta=0.21, p=.03$ ) (controlling for the scanning and the evaluation components of alertness, and for the control variables) was related to the association component of alertness; however, locomotion was not $(\beta=0.00$, $p=$.97) (see Table 3).

Consistent with $\mathrm{H} 2 \mathrm{~b}$, results of the third multiple regression analysis indicated that assessment $(\beta=0.22, p=.02$ ) (controlling for the scanning and the association components of alertness, and for the control variables) was related to evaluation. Locomotion was not related to this component of alertness $(\beta=0.15$, $p=.14)$ (see Table 3).

Alertness Components and Success. Multiple regression analysis was also conducted to test

\footnotetext{
${ }^{1}$ Missing values of the control variables have been replaced with the mean.
} 


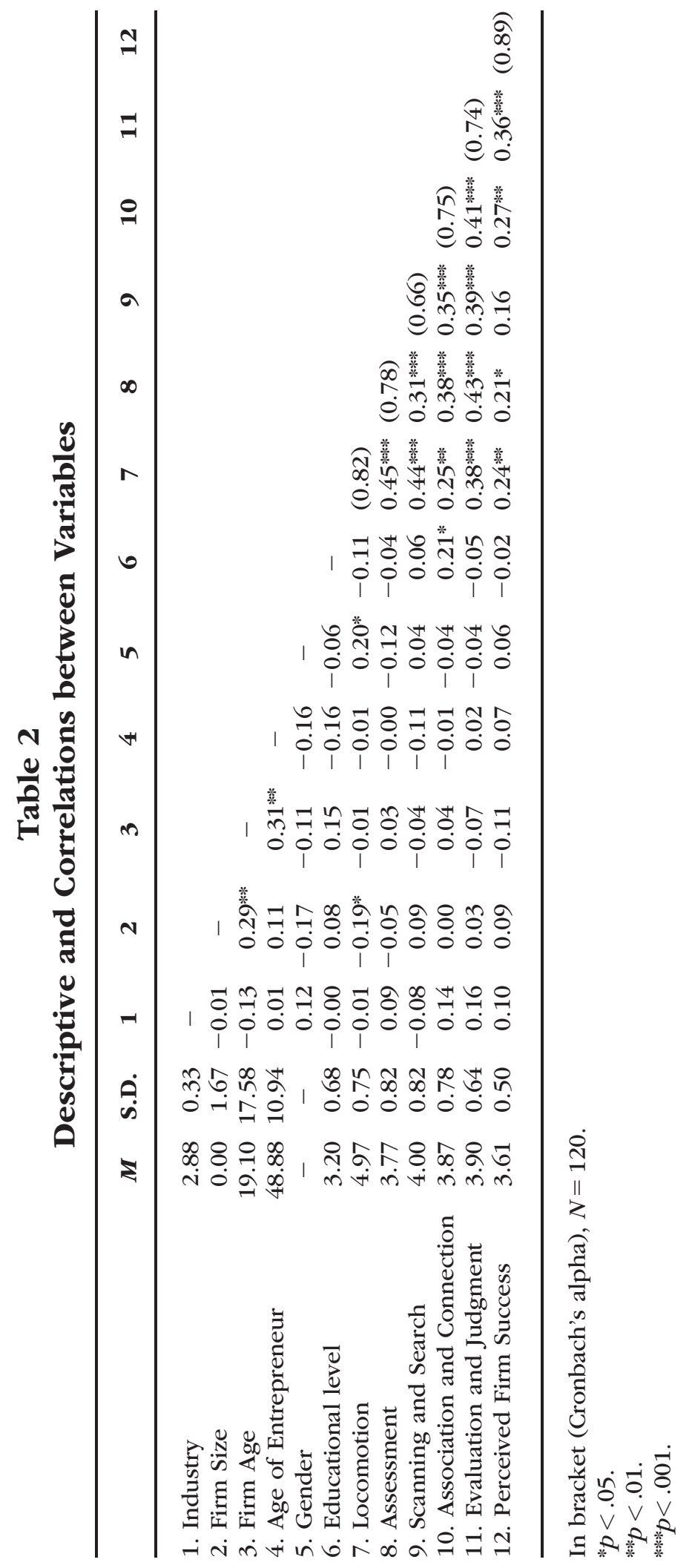


Criteria

Beta

Beta

Beta

\section{Predictors \\ Locomotion \\ Assessment \\ Scanning \\ Association \\ Evaluation \\ Industry \\ Firm Size \\ Firm Age \\ Gender \\ Education \\ $* p<.05$. \\ $* * p<.01$. \\ **** $p<.001$.}

Control Variables

Age of Entrepreneur

$\begin{array}{lcc}0.34^{* * * *} & 0.00 & 0.15 \\ 0.03 & 0.21^{*} & 0.22^{*} \\ - & 0.20^{*} & 0.18^{*} \\ 0.19^{*} & - & 0.21^{* *} \\ 0.19^{*} & 0.23^{*} & -\end{array}$

$-0.14$

$-0.17^{*}$

$-0.08$

$-0.08$

0.00

0.04
0.11

0.11

$-0.04$

0.09

0.05

$-0.10$

$-0.01$

0.06

$-0.04$

0.06

$0.18^{*}$
$\mathrm{H} 3$ examining the relationship between evaluation alertness component and perceived entrepreneurial success. All three alertness components were entered simultaneously to predict success. In addition, previous control variables (firm size, age, industry, entrepreneurs' age, gender, and educational level) were included. Results indicated that the evaluation component of alertness predict perceived firmlevel success $(\beta=0.28, p=.007)$. However, scanning $(\beta=-0.01, p=.90)$ and association ( $\beta=0.17, p=.10$ ) were not related to perceived entrepreneurial success (see Table 4).

Considering all multiple regression analyses conducted, the highest variance inflation factor (VIF) was 1.59 , indicating that multicollinearity was unlikely to be a problem (a general rule is that the VIF should not exceed 10, see Belsley, Kuh, and Welsch 1980).

Mediational Model. The hypothesized model whereby regulatory modes are associated to perceived success indirectly, through their relations with alertness components was investigated through structural equation modeling (SEM). According to parceling procedure (Kim

\section{Table 4 \\ Summary of Results of Multiple Regression Analysis (Success)}

Criteria

Perceived Success Beta

\section{Predictors}

Scanning

Association

$-0.01$

0.17

Evaluation

$0.28 * *$

\section{Control Variables}

Industry $\quad 0.01$

Firm Size $\quad 0.12$

Firm Age $\quad-0.15$

Age of Entrepreneur $\quad 0.09$

Gender $\quad-0.00$

Education $\quad 0.01$

$* * p<.01$.

and Hagtevt 2003), latent variables of locomotion, assessment, and success were defined by three item parcel each (the same of the CFA) and scanning, association and evaluation were defined by the three items of each 


\section{Coefficients Representing Effects of Assessment and Locomotion Ori- entations on Mediators and Success}

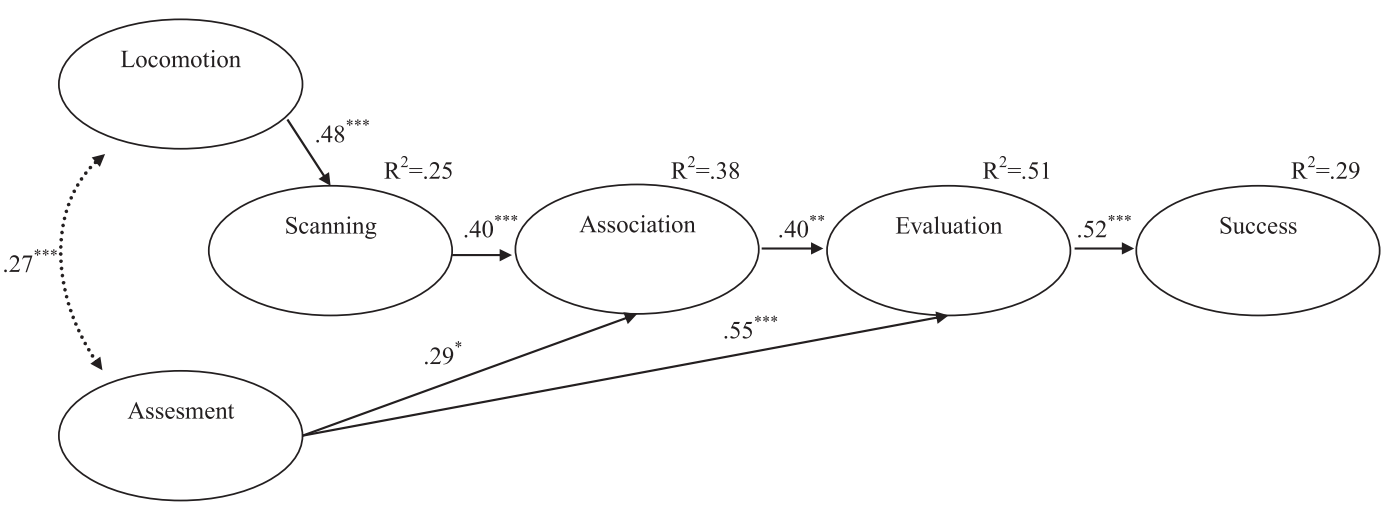

Notes: To simplify the presentation, the observed variables and the control variables have been omitted. ${ }^{*} \boldsymbol{p}<.05$; * $\boldsymbol{p}<.01$; $* * * \boldsymbol{p}<.001$.

subdimension. The relations between these variables were estimated controlling for firm size, firm age, and industry, age, gender, and educational level of entrepreneurs. The fit indexes of the hypothesized model (Figure 1) were acceptable (Hu and Bentler 1999) $\left(\chi^{2}{ }_{(210)}=336.11, p\right.$ $<.001 ;$ RMSEA $=0.07$; NNFI $=0.85$; CFI $=0.88$; SRMSR $=0.08$.

In Figure 2, completely standardized coefficients are reported. As shown in Figure 2, all estimated paths were significant: locomotion was significantly related to scanning component of alertness, which in turn were linked to association component, and association component were linked to evaluation, the latter component of alertness was significantly related to perceived success. The indirect effects from scanning to evaluation (through association) $(b=0.16$, $p<.05$ ) and from scanning to success (through association and evaluation) ( $b=0.08, p<.05)$; and from association to success (through evaluation) $(b=0.20, p<.01)$ were all significant.

Finally, significant indirect effects on perceived success from locomotion $(b=0.04$, $p<.05)$ and assessment $(b=0.28, p<.01)$ were also significant. ${ }^{2}$

\section{Discussion}

Our results indicate that locomotion and assessment regulatory modes play an important role in entrepreneurship. Specifically, both locomotion and assessment were found to be related to a key entrepreneurial ability: identifying and recognizing favorable opportunities (i.e., alertness). Moreover, both regulatory modes, through alertness, have an indirect effect on perceived success.

Consistent with our predictions (H1), entrepreneurs who were high (versus low) on locomotion exhibited a greater tendency to actively scan and for market information suggesting opportunities; further they also reported greater business success. While, again consistent with our hypothesis (H2a), entrepreneurs who were high (versus low) on assessment appeared to be more likely to consider multiple options and therefore better able to associate and connect

\footnotetext{
${ }^{2}$ We compared our model with an alternative model with direct effects of regulatory modes on perceived success. Overall the results of the SEM analysis confirmed that this new model does not add new information: either locomotion $(b=0.32$, n.s. $)$ or assessment $(b=-0.27$, n.s. $)$ has direct effects on perceived success. The fit indexes of the alternative models are: $\left(\chi^{2}{ }_{(208)}=334.98, \quad p<.001 ; \quad\right.$ RMSEA $=0.072 ; \quad$ NNFI $=0.84 ; \quad$ CFI $=0.88$; SRMSR $=0.079 ; \mathrm{NNFI}=0.84$ ). Since there is no difference between our model and alternative model $\left(\Delta \chi^{2}{ }_{(2)}=1.13\right.$, n.s. $)$, our model has to prefer for the parsimony principle.
} 
available information in different ways-in a sense, "thinking outside the box" where opportunities are concerned. In addition, the hypothesized positive relationship between assessment and evaluation component of alertness was supported (H2b). Assessment, which reflects concern about comparative evaluations to make the best decision before taking action (Kruglanski et al. 2000) was associated with the preference for evaluating and estimating the potential profitability of identified opportunities (Tang et al. 2012). That is, individuals who were high (versus low) in assessment orientation exhibited a stronger tendency to make carefully evaluate potential opportunities, and so choose the best (i.e., potentially profitable) ones.

It is important to note that "the three dimensions of alertness complement each other and give the individual a foundation on which to identify new business ideas" (Tang et al. 2012, p. 34). This is why the alertness process is often viewed as a pre-actional phase of entrepreneurship, one involving both regulatory modes, as suggested by Scholer and Higgins (2012). In fact, entrepreneurs high in both locomotion and assessment are more alert and, in turn, their ability to search for information, to recognize patterns in it, and to evaluate business opportunities may contribute to their success. Perhaps, locomotors' action orientation predicts the time and resources spent by small firms' founders in searching for, or generating information flow. Further, locomotors' high intrinsic motivation and their willingness to expend high levels of effort contribute to their engagement in intense information collection efforts. Once resources have been committed to the search and scanning, however, effective evaluation becomes important. Such evaluation may involve a careful feasibility analysis, which addresses the question of whether the proposed combination of resources can actually yield economic success (Ardichvili et al. 2003). In this sense, the assessors' concern with comparative aspects is fundamental.

Our data also provide support for the mediational model proposed, a model suggesting that regulatory modes are related to firm performance through the mediation of the three components of alertness. Locomotion is associated with firm performance through its role as a kind of "engine" for active search and scanning, which in a sense, is the initial phase of the opportunity recognition process; assessment, in contrast, is associated with firm performance through its positive relationship with association and evaluation, subsequent phases in the entrepreneurial process. Thus, in a sense, the most advantageous pattern for entrepreneurs appears to be a combination of the two regulatory modes. They operate in complementary ways, at least with respect to the crucial task of opportunity recognition.

The relationship between locomotion and assessment on the one hand, and small firm's success on the other, provide additional evidence for the suggestion that individual-level variables are indeed related to business success (Rauch and Frese 2000; Rauch and Frese 2007a).

In relation to the regulatory modes theory (Kruglanski et al. 2000), the present findings add new information on the relationship between regulatory modes and specific aspects of entrepreneurship that have, prior to this research, not been the focus of empirical research.

Since regulatory modes can be also situationally induced (Avnet and Higgins 2003), it is important to note that the present dynamic between regulatory modes, alertness and firm level success, could lead to potentially useful applications in organizational settings. Specifically, understanding the circumstances under which entrepreneurs become locomotors could be useful in improving their mind-set and helping them to attain greater efficiency in searching for potentially valuable business opportunities. Similarly, situations that may induce entrepreneurs to become more assessment oriented may lead to more accurate evaluations of individuated opportunities, which can also contribute to firm performance. It is important to note, however, that the evidence obtained in this study relies on self-reported data. Therefore, although in social sciences using the same source to obtain data on predictor and criterion variables is commonly accepted as a useful and informative approach, this procedure is problematic because it can raise concerns about common method bias (e.g., consistency effect, social desirability) (Podsakoff et al. 2003). We minimized common method variance methodologically protecting respondent anonymity and statistically using SEM (Pedhazur and Schmelkin 1991). In addition, our measure of success is a subjective assessment provided by respondents; future research could include other measures (hetero-evaluations or objective criteria) of firm performance. Specifically, beyond perceived business success, $n$ the measure used this study, 
objective data (e.g., financial data such as, profit growth, firm size growth) could be used to enhance predictive and construct validity.

Another possible direction for future research could involve determining whether the present model applies not only to actual entrepreneurs, but also to individuals considering entrepreneurship as a future course of action, that is nascent entrepreneurs. Such research could employ a longitudinal design, which would shed light on how regulatory modes influence intentions to become an entrepreneur (e.g., Zhao et al. 2010). A longitudinal design on regulatory modes and alertness would also permit investigation of the three alertness components as steps in the entrepreneurial opportunity recognition process, rather than as individual traits, thus avoiding the commonly accepted practice of interviewing entrepreneurs at one point in time, which results in a collapse all the stages into the time at which such data are collected (Gaglio and Katz 2001).

In conclusion, the evidence reported in the present research, although informative in several ways, also suggests the need for further investigations to fully explore the relationships between regulatory modes and key aspects of entrepreneurship. Such research can help clarify how entrepreneurs approach to new situations-by acting now (a locomotion regulatory mode), or by intending to act only after careful consideration of all relevant information (assessment mode)—can play a key role in their ongoing efforts to convert their ideas into reality-available (and profitable) new ventures.

\section{References}

Acs, Z. J. (1992). "Small Business Economics: A Global Perspective," Challenge 35(6), 38-44.

Amato, C. (2013). Psicologia dell'imprenditore. Anatomia di una vocazione. [Entrepreneurship's Psychology. A Vocation's Anatomy]. Rome, IT: Armando Editore.

Amato, C., A. Pierro, A. Chirumbolo, and G. Pica (2014). "Regulatory Modes and Time Management: How Locomotors and Assessors Plan and Perceive Time," International Journal of Psychology 49(3), 192-199.

Ardichvili, A., R. Cardozo, and S. Ray (2003). "A Theory of Entrepreneurial Opportunity Identification and Development," Journal of Business Venturing 18(1), 105-123.
Avnet, T., and E. T. Higgins (2003). "Locomotion, Assessment, and Regulatory Fit: Value Transfer from 'How' to 'What'," Journal of Experimental Social Psychology 39(5), 525-530.

Baas, M., C. K. W. De Dreu, and B. A. Nijstad (2008). "A Meta-Analysis of 25 Years of Mood-Creativity Research: Hedonic Tone, Activation, or Regulatory Focus?" Psychological Bulletin 134(6), 779-806.

Bagozzi, R. P. (1994). Principles of Marketing Research. Cambridge, MA: Blackwell.

Bagozzi, R. P., and T. F. Heatherton (1994). "A General Approach to Representing MultiFaceted Personality Constructs: Application to State Self-Esteem," Structural Equation Modeling: An Interdisciplinary Journal 1(1), 35-67.

Baron, R. A. (2006). "Opportunity Recognition as Pattern Recognition: How Entrepreneurs 'Connect the Dots' to Identify New Business Opportunities," Academy of Management Perspectives 20(1), 104-119.

__ (2007). "Behavioral and Cognitive Factors in Entrepreneurship: Entrepreneurs as the Active Element in New Venture Creation," Strategic Entrepreneurship Journal 1(1-2), 167-182.

Baron, R., and S. Shane (2008). Entrepreneurship: A Process Perspective. 2nd ed. Cincinnati, $\mathrm{OH}$ : Cengage-Southwestern.

Baron, R. A., J. Tang, and K. M. Hmieleski (2011). "The Downside of Being 'Up': Entrepreneurs' Dispositional Positive Affect and Firm Performance," Strategic Entrepreneurship Journal 5(2), 101-119.

Baum, J. R. and E. A. Locke (2004). "The Relationship of Entrepreneurial Traits, Skill, and Motivation to New Venture Growth," Journal of Applied Psychology 89(4), 587-598.

Baum, J. R., E. A. Locke, and K. G. Smith (2001). "A Multi-Dimensional Model of Venture Growth," Academy of Management Journal 44(2), 292-302.

Belsley, D. A., E. Kuh, and R. E. Welsch (1980). Regression Diagnostics: Identifying Influential Data and Sources of Collinearity. New York: John Wiley.

Betsch, C. (2011). "Chronic Preferences for Intuition and Deliberation in Decision Making. Lessons Learned About Intuition from an Individual Differences Approach," in Intuition in Judgement and Decision Making. Eds. H. Plessner, C. Betsch, and T. 
Betsch. New York, NY: Taylor \& Francis Group, 231-251.

Brandstätter, H. (1997). "Becoming an Entrepreneur-A Question of Personality Structure?," Journal of Economic Psychology 18(2-3), 157-177.

(2011). "Personality Aspects of Entrepreneurship: A Look at Five Meta-Analyses," Personality and Individual Differences 51(3), 222-230.

Braun, R., and M. B. A. aus Bornheim (2007). "Opportunity Recognition as Creative Thinking. Theoretical Considerations and Empirical Results on Cognitive Styles and Abilities in Discovering Entrepreneurial Opportunities," Ph.D. dissertation, University of Wuppertal, 175-195.

Brigham, K. H., J. O. D. Castro, and D. A. Shepherd (2007). "A Person-Organization Fit Model of Owner-Managers' Cognitive Style and Organizational Demands," Entrepreneurship Theory and Practice 31(1), 2951.

Ciavarella, M. A., A. K. Buchholtz, C. M. Riordan, R. D. Gatewood, and G. S. Stokes (2004). "The Big Five and Venture Success: Is There a Linkage?," Journal of Business Venturing 19(4), 465-483.

Collins, C. J., P. J. Hanges, and E. A. Locke (2004). "The Relationship of Achievement Motivation to Entrepreneurial Behavior: A Meta-Analysis," Human Performance 17(1), 95-117.

Cooper, A. C., C. Y. Woo, and W. C. Dunkelberg (1988). "Entrepreneurs' Perceived Chances for Success," Journal of Business Venturing 3(2), 97-108.

Dyer, J. H., H. B. Gregersen, and C. Christensen (2008). "Entrepreneur Behaviors, Opportunity Recognition, and the Origins of Innovative Ventures," Strategic Entrepreneurship Journal 2(4), 317-338.

European Union (2003). "Commission Recommendation of 6 May 2003 Concerning the Definition of Micro, Small and MediumSized Enterprises," Official Journal of The European Union (N. L124/36 from 20.5.2003). Brussels: Author.

Gaglio, C. M. (2004). "So What Is an Entrepreneurial Opportunity?," in Opportunity Identification and Entrepreneurial Behavior. Ed. J. E. Butler. Charlotte, NC: Information Age Publishing Inc, 115-134.

Gaglio, C. M., and J. A. Katz (2001). "The Psychological Basis of Opportunity Identifica- tion: Entrepreneurial Alertness," Small Business Economics 16(2), 95-111.

Göbel, S. and M. Frese (1999). "Persönlichkeit, Strategien und Erfolg bei Kleinunternehmern [Personality, Strategies and Success of Small Business Owners]," in Unternehmerisch erfolgreiches Handeln [Successful Venture Behaviour]. Eds. K. Moser, B. Batinic, and J. Zempel. Göttingen, Germany: Verlag fur Angewandte Psychologie, 93-113.

Herron, L., and R. B. Robinson (1993). "A Structural Model of the Effects of Entrepreneurial Characteristics on Venture Performance," Journal of Business Venturing 8(3), 281-294.

Higgins, E. T. (2006). "Value from Hedonic Experience and Engagement," Psychological Review 113(3), 439-460.

Higgins, E. T., A. W. Kruglanski, and A. Pierro (2003). "Regulatory Mode: Locomotion and Assessment as Distinct Orientation," in Advances in Experimental Social Psychology. Ed. M. P. Zanna. San Diego, CA: Academic Press, Vol. 35, 294-345.

Hillary, R. (Ed.) (2000). Small and Mediumsized Enterprises and the Environment: Business Imperatives. Sheffield, UK: Greenleaf Publishing.

Hmieleski, K. M., and R. A. Baron (2009). “Entrepreneurs' Optimism and New Venture Performance: A Social Cognitive Perspective," Academy of Management Journal 52(3), 473-488.

Hu, L. T., and P. M. Bentler (1999). "Cutoff Criteria for Fit Indexes in Covariance Structure Analysis: Conventional Criteria Versus New Alternatives," Structural Equation Modeling: A Multidisciplinary Journal 6(1), 1-55.

Iverson, R. D., and C. Maguire (2000). "The Relationship Between Job and Life Satisfaction: Evidence from a Remote Mining Community," Human Relations 53(6), 807-839.

Kaish, S., and B. Gilad (1991). "Characteristics of Opportunities Search of Entrepreneurs Versus Executives: Sources, Interests, General Alertness," Journal of Business Venturing 6(1), 45-61.

Kickul, J., L. K. Gundry, S. D. Barbosa, and L. Whitcanack (2009). "Intuition Versus Analysis? Testing Differential Models of Cognitive Style on Entrepreneurial Self-Efficacy and the New Venture Creation Process," Entrepreneurship Theory and Practice 33(2), 439-453. 
Kirzner, I. M. (1973). Competition and Entrepreneurship. Chicago, IL: University of Chicago Press.

(1979). Perception, Opportunity, and Profit. Chicago, IL: University of Chicago Press.

Kim, S., and K. A. Hagtvet (2003). "The Impact of Misspecified Item Parceling on Representing Latent Variables in Covariance Structure Modeling: A Simulation Study," Structural Equation Modeling 10, 101-127.

Koellinger, P., M. Minniti, and C. Schade (2007). "II Think I Can, I Think I Can': Overconfidence and Entrepreneurial Behavior," Journal of Economic Psychology 28(4), 502-527.

Kruglanski, A. W., E. Orehek, E. T. Higgins, A. Pierro, and I. Shalev (2010). "Modes of SelfRegulation: Assessment and Locomotion as Independent Determinants in Goal Pursuit," in Handbook of Personality and Self Regulation. Ed. R. H. Hoyle. Chichester, UK: Blakwell Publishing, 375-402.

Kruglanski, A. W., E. P. Thompson, E. T. Higgins, M. N. Atash, A. Pierro, J. Y. Shah, and S. Spiegel (2000). "To "Do the Right Thing" or to "Just Do It": Locomotion and Assessment as Distinct Self-Regulatory Imperatives," Journal of Personality and Social Psychology 79(5), 793-815.

Leutner, F., G. Ahmetoglu, R. Akhtar, and T. Chamorro-Premuzic (2014). "The Relationship between the Entrepreneurial Personality and the Big Five Personality Traits," Personality and Individual Differences 63(1), 58-63.

Lumpkin, G. T., and G. G. Dess (1996). "Clarifying the Entrepreneurial Orientation Construct and Linking It to Performance," Academy of Management Review 21(1), 135-172.

Markman, G. D., and R. A. Baron (2003). "Person-Entrepreneurship Fit: Why Some People Are More Successful as Entrepreneurs than Others," Human Resource Management Review 13(2), 281-301.

Mauro, R., A. Pierro, L. Mannetti, E. T. Higgins, and A. W. Kruglanski (2009). "The Perfect Mix Regulatory Complementarity and the Speed-Accuracy Balance in Group Performance," Psychological Science 20(6), 681-685.

Miron, D. and D. C. McClelland (1979). "The Impact of Achievement Motivation Training on Small Businesses," California Management Review 21(4), 13-28.

Murphy, G. B., J. W. Trailer, and R. C. Hill (1996). "Measuring Performance in Entrepreneurship Research," Journal of Business Research 36(1), 15-23.

Pedhazur, E., and L. Schmelkin (1991). Measurement, Design and Analysis: An Integrated Approach. New York: Holt, Rinehart \& Winston.

Pierro, A., G. Pica, R. Mauro, A. W. Kruglanski, and E. T. Higgins (2012). "How Regulatory Modes Work Together: LocomotionAssessment Complementarity In Work Performance," TPM - Testing, Psychometrics, Methodology in Applied Psychology 19(4), 247-262.

Pierro, A., A. W. Kruglanski, and E. T. Higgins (2006a). "Progress Takes Work: Effects of the Locomotion Dimension on Job Involvement, Effort Investment, and Task Performance in Organizations," Journal of Applied Social Psychology 36(7), 1723-1743.

___ (2006b). "Regulatory Mode and the Joys of Doing: Effects of 'Locomotion' and 'Assessment' on Intrinsic and Extrinsic TaskMotivation," European Journal of Personality 20(5), 355-375.

Podsakoff, P. M., S. B. MacKenzie, J. Y. Lee, and N. P. Podsakoff (2003). "Common Method Biases in Behavioral Research: A Critical Review of the Literature and Recommended Remedies," Journal of Applied Psychology 88(5), 879-903.

Rauch, A., and M. Frese (1997). "Does Planning Matter? Relations between Planning and Success in Small Enterprises in Ireland and in Germany," Paper presented at the 42nd World Conference of the ICSB International Council for Small Business, San Francisco.

(2000). "Psychological Approaches to

Entrepreneurial Success: A General Model and an Overview of Findings," in International Review of Industrial and Organizational Psychology. Eds. C. Cooper and I. Robertson. Chichester, UK: Wiley, 101-142.

___ (2007a). "Born to Be an Entrepreneur? Revisiting the Personality Approach to Entrepreneurship," in The Psychology of Entrepreneurship. Eds. J. R. Baum, M. Frese, and R. A. Baron. Mahwah, NJ: Erlbaum, 41-46.

(2007b). "Let's Put the Person Back into Entrepreneurship Research: A MetaAnalysis on the Relationship Between 
Business Owners' Personality Traits, Business Creation, and Success," European Journal of Work and Organizational Psychology 16(4), 353-385.

Sambasivan, M., M. Abdul, and Y. Yusop (2009). "Impact of Personal Qualities and Management Skills of Entrepreneurs on Venture Performance in Malaysia: Opportunity Recognition Skills as a Mediating Factor," Technovation 29(11), 798-805.

Scholer, A. A., and E. T. Higgins (2012). "Commitment to Change from Locomotion Motivation During Deliberation," Motivation and Emotion 36(2), 114-129.

Shane, S., L. Kolvereid, and P. Westhead (1991). "An Exploratory Examination of Reasons Leading to New Firm Formations across Country and Gender," Journal of Business Venturing 6(6), 431-446.

Shane, S., and N. Nicolaou (2013). "The Genetics of Entrepreneurial Performance," International Small Business Journal 31(1), 473-495.

Stevenson, H. H., M. J. Roberts, and H. I. Grousbeck (1985). New Business Ventures and the Entrepreneur. Homewood, IL: Irwin.

Tang, J. (2009). "Exploring the Constitution of Entrepreneurial Alertness: The Regulatory Focus View," Journal of Small Business and Entrepreneurship 22(3), 221-238.

Tang, J., K. M. Kacmar, and L. Busenitz (2012). "Entrepreneurial Alertness in the Pursuit of New Opportunities," Journal of Business Venturing 27(1), 77-94.
Tornau, K., and M. Frese (2013). "Construct Clean-up in Proactivity Research: A MetaAnalysis on the Nomological Net of WorkRelated Proactivity Concepts and their Incremental Validities," Applied Psychology 62(1), 44-96.

Van Gelderen, M., M. Brand, M. van Praag, W. Bodewes, E. Poutsma, and A. van Gils (2008). "Explaining Entrepreneurial Intentions by Means of the Theory of Planned Behavior," Career Development International 13(6), 538-559.

Venkatraman, N., and V. Ramanujam (1986). "Measurement of Business Performance in Strategy Research: A Comparison of Approaches," Academy of Management Review 11(4), 801-814.

Yu, T. F. L. (2001). "Entrepreneurial Alertness and Discovery," The Review of Austrian Economic 14(1), 47-63.

Weber, E. U., and P. G. Lindemann (2011). "From Intuition to Analysis. Making Decisions with Your Head, Your Heart, or by the Book," in Intuition in Judgment and Decision Making. Eds. H. Plessner, C. Betsch, and T. Betsch. New York, NY: Taylor \& Francis Group, 191-209.

Witteman, C., J. van den Bercken, L. Claes, and A. Godoy (2009). "Assessing Rational and Intuitive Thinking Styles," European Journal of Psychological Assessment 25(1), 39-47.

Zhao, H., S. E. Seibert, and G. T. Lumpkin (2010). "The Relationship of Personality to Entrepreneurial Intentions and Performance: A Meta-Analytic Review," Journal of Management 36(2), 381-404. 